\title{
Localization Research on the College Olympic Education in the Post-Beijing Olympic Era
}

\author{
Zhao Yang \\ College of Management Shenzhen Uniyersity \\ Shenzhen, China \\ zhgoat123@sina.com.cn
}

Key words: globalization; Olympics; education; college; localization

Abstract: The sports globalization is quietly going on with the course of the globalization, and expanding rapidly in the whole world with the booming of modern sports. In the course of the globalization, the Olympic Games develop rapidly which becomes the spectacular global phenomenon. The Olympic spirit bases on the western civilization, but only the western civilization itself cannot answer the questions and challenges in front of the Olympic spirit. It needs to seek helpful enlightenment from other culture types. China's success of holding the Olympics shows that the college has become the battle position of the Olympics education. The Olympics education of Chinese colleges in the post-Olympic era should not only adhere to the universality, but also ensure the correctness of the Olympics education direction as well as the localization to improve the implementation effect.

\section{Introduction}

With the development with the human intercourse, the communication among different culture models is more and more extensive and deep; the degree of mutual acknowledgment and integration is constantly increasing, which forms certain culture connectivity with common sense (the consistency in the values and living style), This is the culture globalization as an important part of the globalization. The rapid development of modern scientific technology shortens the space-time distance among people, which provides the material foundation for the culture globalization. Although there are full of identical trend strength and conflicts among nations and countries, and the restructuring and new changes of the global culture make different cultures take turns in the frequent mutual movement, but this is just the process of the formation of the global value. The culture globalization has become the integral part of the globalization process; while in the process of the culture globalization, the mutual permeation and integration is not only the objective phenomenon, but also the irreversible trend. With the deepening of the culture globalization, people with different culture backgrounds will more and more consider the issue from the overall mankind and accept the commonness in the human culture, and thus smoothly complete the transfer from national culture, regional culture to global culture.

There is difference and interdependency relationship among people. As such, the holiness of people and the universal humanity become the culture idea that maintains the humankind intercommunity and consistency. However, this does not mean that the global culture will really be unified or assimilated due to such ideals, because such culture ideals are in the process of localization in different countries and regions, and thus show great difference. The globalized 
culture is not the one built on basis of the geography division, but on basis of the main body of the culture (people). If the formation of the global value is only the expansion and cover of certain single culture, it is just the deviation from the globalization spirit. The future of the culture globalization will not go to the absolute "identical trend" and form new single culture. Instead, the diversifying cultures will achieve mutual understanding through dialogue to seek common points while reserving difference. From the historical point of view, although the history of the various cultures may be long or short, they are differentiated from high or low, or good or bad. They all contribute positively to the progress of the human culture in their own ways. Just because of difference, various cultures can learn each other and make common progress. If forcing them to be the same, it will only cause the human culture to lose power and become rigid and declined. The culture development is the hope and power for the human to get rid of the bother of wars, and also the thought base for the world to be harmonious. Without the communication, dialogue and understanding among cultures, it is difficult to realize peace and development. Only by tolerating and respecting different cultures, can they learn each other, learn from others' strong points to offset one's weakness, seek common points while reserving difference to achieve joint progress and build the harmonious world with long peace and co-prosperity. From the long term, in the progress of the culture globalization, the globalization may be resisted by the culture localization. The future development of the world culture largely depends on the interaction formed by the opposition and dialogue between globalization and localization. The culture particularity (aboriginality) will finally be integrated into the culture universality. The special values of culture will absorb more common values and flow into the world mainstream culture when the common values are broadly accepted. Therefore, there will be double trends of "sticking to the traditional" and "pursuing common values" in the development of today's world culture.

\section{The Beijing Olympic Games made successful exploration in the localization of Olympics education.}

The sports globalization is quietly going on with the course of the globalization, and expanding rapidly in the whole world with the booming of modern sports. The modern Olympic Games can be the most typical symbol of the sports globalization. The Olympic Games originated from the capitalism industrialization in west Europe. It is based on the solid social economic, political and cultural foundation and follows the requirement of social development and the trend of the sports development, which is an extremely hard and bitter social practice of the human society starting after the industrial civilization. In 1894, the first International Sports Education Representative Conference well designed and held by the father of the Olympics Mr. Coubertin in Sorbonne, Paris, which symbolizes the born of modern Olympic Games. Mr. Coubertin drafted the constitution of International Olympic Committee and explained the philosophical foundation, education and aesthetic significance of the Olympic Games, which establishes the theoretic base for the Olympic Games and develop it to a permanent sports and peace campaign. The International Olympic Committee is a permanent international institution with the corporate capacity. It is intended to be the official name of the Olympic organization, which shows the willing of the Olympic Games globalization, i.e. the Olympic Games are firstly international and then Olympics. As one of the representative products of the whole human society civilization, modern Olympic Games has become the incomparable culture phenomenon and carrier of today's world by the constant self-development, improvement and amendment. The Olympics spirit emphasizes friendship, unity and mutual understanding. The purpose is to promote the communication among the world countries and people of various nations and build the harmonious culture atmosphere. It is in such 
atmosphere that people can possibly get rid of various prejudice of their respective culture, which can enable the international communication, mutual help and mutual learning advocated by Olympic Games to be finally achieved. The modern Olympic Games are not only a grand meeting for sports, but also a grand meeting for culture. It is the huge stage for global people to reveal their style, tradition, emotion, spiritual features and culture. The diversified world cultures displayed in the Olympic Games period have their own merits. However, they do not oppose and reject each other; instead, they run parallel without confliction; con-exist without harming, showing the characteristics of harmonious co-existence and mutual tolerance. The Olympics ideal expresses people's pursuit of truth, goodness and beauty as well as the highly praise of the sports morality. In the initial period of set up, this event is committed to fair competition, advocate friendly affection and harmony. It is a pure culture event with deep ideological implication. Under the globalization background, the Olympic Games have achieved the unprecedented development.

In the course of the globalization, the Olympic Games develop rapidly which becomes the spectacular global phenomenon. However, the process of the Olympic Games globalization accompanies such a trend, i.e. emphasizing the western sports culture and requesting other non-western sports culture to keep up with the western sports culture. In the long term, it is necessary to emphasize the culture diversity of the Olympic Games. The important reason is that the universality of the Olympic Games can only be realized through the culture diversity. It relates to the basic principle of the Olympic Games and the foundation of the existence of the Olympics. With the interaction of the contemporary science, humanities and biological ethnics, the culture diversity and the dialogue way of the Olympic Games has become one of the important symbols of the human culture development in the globalization era. In the development of the Olympic Games, there are also problems of over-commercialization, abuse of stimulant, etc. The stimulant, soccer fraud, and the underground sports gambling in the minority places prejudice the lofty Olympics spirit. The Olympics spirit bases on the western civilization, but only the western civilization itself cannot answer the questions and challenges in front of the Olympic spirit. It needs to seek helpful enlightenment from other culture types. The Chinese traditional culture advocates not only "harmony" but also "harmony in diversity" (Zi Lu, the Analects of Confucius), which has important significance in the globalization era. Beijing put forward the three ideas of "Green Olympics, scientific and technological Olympics and human Olympics", and finally successfully held the 2008 Olympic Games. Its important contribution is to transfer the idea of humane Olympics into practice and meanwhile try to explore the localization of the Olympics education. The humane Olympics are the soul and light-spot. The Chinese traditional culture and the eastern philosophy wisdom provides the enlightenment for the questions and challenges in front of the Olympics culture and input new vitality in it. The 2008 Olympic Games created the localized and hipping Chinese Olympics education model with Chinese characteristics, which contributes to the Olympic Games and leaves rich heritage to Chinese education.

\section{The post-Olympic era needs to further deepen the Olympics localization education in colleges.}

Except for such old social culture phenomenon as the religion, the Olympic Games can be called a social culture phenomenon with the longest history. The purpose for the creator of the Olympic Games Mr. Coubertin to revive the Olympic Games is to spread the Olympics ideal, and thus educate the youth and promote the harmonious development of the youth's mind and body in a new angle and a new way. On basis of this thought, the basic purpose of Mr. Coubertin is not to use the Olympic Games to advance the competing events, but to include the competing events into 
education and further include the education in to the human culture and life. In the Olympics Charter made by the International Olympic Committee, the wording "education" occurs many times in the articles of "olympism", "aim of the Olympics Games", "mission of the International Olympic Committee" and "functions of the International Olympic Committee". This nature of the Olympic Games determines that its nature is education and education is the starting point and home to return for the Olympics Game.

The course of modern Olympic Games is not only the history of the development of the world sports, but also the history of the development and communication of the world diversifying cultures. The lifelong honored chairman of International Olympic Committee, Samaranch, said if the culture was not included, the city holding the Olympic Games is not complete. As the famous historical culture city and modern international metropolitan, Beijing held the 29th Olympic Games, and greatly promoted the communication and integration of the eastern and western cultures, and enriched the implication of the Olympics spirit. After the successful bidding to host the Olympic Games, Chinese Olympics education rapidly expanded to various schools. Many forms of the Olympics education activities play a positive role in popularizing the Olympics knowledge, spreading the Olympics ideal, enriching and improving the students' spiritual world, shaping the times moral character of loving the country and self-support, open and confidence, zeal and friendship, and struggling to move forward. As the talent cultivation base and public opinion position, as well as one of the social agencies connecting the sports and education, Chinese colleges undertake the responsibility for knowledge innovation and knowledge spread, as well the task to development the sports and spread the sports value. For several years, especially during the period of Beijing Olympic Games, serving for the Olympic Games has become one direct and meaningful form of the colleges to serve for the society. Developing the Olympics education in colleges not only popularizes the Olympics knowledge, spreads the Olympics spirit and promotes the development of the Olympic Games, but also enriches the sports education in colleges, promotes the integration of the morality, intellect and sports education, teaches through sports and fully improves the students' overall quality. The special role of the colleges and the students shows that the development of the Olympics education in colleges has the significant meaning for spreading the Olympics spirit, carrying on the advanced culture of Chinese nation, absorbing the excellent foreign culture, constructing the new socialism culture with Chinese characteristics which reflects the feature of the times, and promoting the human's harmonious development and social progress. China's successful hosting the Olympic Games indicates that colleges have become the main position of Olympics education. By summarizing the experience, we may find that the localization of the Olympics education in colleges is the key of success. The colleges in different regions make use of the regional resource advantage to integrate the Olympics education and the region features, traditional culture as well as the school characteristics; enhance the combination of the Olympics education and the school reform of the morality, sports and the new curriculum; promote the effective development of the Olympics education in school; through colorful practice, infiltrate the Olympics ideal, popularize the Olympics knowledge, advocate the Olympics spirit and spread the Olympics culture to make the massive undergraduates pay close attention to the Olympics, know the Olympics, participate in the Olympics, experience the Olympics and gain benefits from the Olympics; and thus creates good atmosphere for the preparation of Beijing Olympic Games, and provides the service and practice support for the success of the Olympic Games. These traditional forms like the national art used by Chinese colleges to display the Olympic Games and culture have 
the characteristic of the perfect integration of the east and west, tradition and modern, and the content and form.

Beijing Olympic Games left a deep memory to the people of the whole world. From the city construction to the social atmosphere, from the material heritage to the spirit heritage, all bring the new flavor and appearance to the whole China. It brings the world with many surprising changes either in the spirit aspect, or in the aspect of the Olympics spirit, volunteer spirit and the sports spirit. In the meantime, the world also has certain effect on Beijing Olympic Games. It makes the whole country more open and let all people have more energy to feel the Olympic Games. Especially, Chinese culture displays its grace as the world strength in a gorgeous bearing; realizes the communication of the human civilization; improves the integration of Chinese culture and the Olympics culture; further carries on Chinese nation's excellent tradition culture; enhances Chinese people's culture confidence; and improves the country's culture soft strength. The rich heritage left by Beijing Olympics culture to the world will be eternal. The Beijing Olympic Games of world interest ended. For the undergraduate in colleges, one of the largest heritages is the Olympics education they had in the Olympia circle which integrates with local culture. The value of such heritage is inestimable and irreplaceable!

\section{Conclusions}

The Beijing Olympic Games has been ended for 8 years till 2016. The practice of the Olympics education in college shows that the Olympics education localization should be vigorously developed after the Beijing Olympic Games. It is necessary to carefully research and summarize the successful experience and spiritual wealth of the Olympics education localization in the Beijing Olympic Games; inherit the Olympic heritage; advance the Olympics spirit and transfer the spiritual wealth accumulated by college students during the Olympics period into the strong driving force for self-growing. In the post Olympics era, the idea and social value that should be spread by the Olympics education in Chinese colleges is still dynamic. It does not use certain country or certain culture as the model; instead, it is summarized and derived from the civilization achievements from all countries in the world. Chinese undergraduate should insist that as the representative of the eastern culture, Chinese traditional culture should be an integral part of the Olympics culture, and enrich and supplement the Olympics culture to make it more diversified. The Olympics education of Chinese colleges in the post-Olympic era should not only adhere to the universality, but also ensure the correctness of the Olympics education direction as well as the localization to improve the implementation effect.

\section{References}

[1] Zang Lingling: submitted to Modern education management (2013)

[2] Tu Chuanfei , Chen Zhidan and Yan Wei : submitted to Journal of Xi'an Physical Education University (2009)

[3] Wang Jian,Song Jixin and Zhao Yongping: submitted to Journal of Shenyang Sport University (2010)

[4] Pei Dongguang: submitted to Sports Culture Guide (2009)

[5] Chen Anping, Meng Li: submitted to Journal of Shanxi University (Philosophy \& Social Science) (2010) 
[6] Xu Guoqi: submitted to Ninth International Symposium for Olympic Research ( 2008) 